\title{
Aus reiner Freude am guten Angebot
}

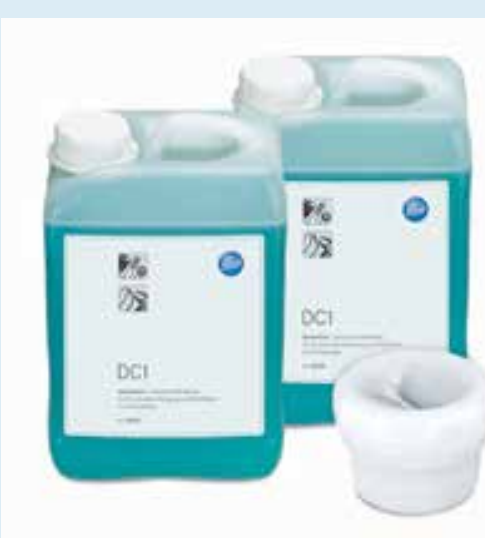

Das DC1 Reinigungs- und Desinfektionsmittel und einen Fräsator aus Opalglas gibt es jetzt zum einmaligen Aktionspreis! Wer sich für $2 \times 3$ Liter DC1 von Komet und die praktische Desinfektionswanne für Instrumente entscheidet, erhält die Ware für nur 139,-€. Das freut nicht nur den Geldbeutel, sondern auch das Instrumentarium. Oft führen aggressive Reinigungsund Desinfektionsmittel dazu, dass es, insbesondere beim Überschreiten der
Einlegezeit, angegriffen wird - nicht so bei der materialverträglichen und wirtschaftlichen Komplettlösung DC1. Die viruzide (wirksam entsprechend den Anforderungen des RKI gegen behüllte Viren inkl. HBV, HCV und HIV), bakterizide (inkl. TBC und MRSA) und fungizide Wirkung ist bereits bei einer $1 \%$ igen Konzentration von DC1 nach 60 min gegeben.

Nach einer Pressemitteilung der Komet Dental Gebr. Brasseler GmbH \&

\section{Co. KG, Lemgo}

